\title{
ANALISIS PELAKSANAAN PENDIDIKAN KARAKTER DI SMKN 1 WONOSARI (Studi Pada Pembelajaran Sejarah)
}

\author{
S U Y A N T I * \\ Tenaga Pengajar Universitas PGRI Madiun \\ Jl. Setia Budi No. 85 Madiun, Jawa Timur, Indonesia
}

\begin{abstract}
ABSTRAK
Tujuan dari penelitian ini adalah (1) perencanaan pendidikan karakter melalui pembelajaran sejarah, (2) pelaksanaan pendidikan karakter melalui pembelajaran sejarah, dan (3) penilaian pendidikan karakter dalam kegiatan belajar mengajar. Penelitian ini menggunakan kasus tunggal karena penelitiannya hanya dilakukan pada satu sasaran (satu lokasi atau satu objek), sehingga strategi penelitian yang relevan adalah studi kasus (study case). Tehnik pengumpulan datanya menggunakan teknik nontes (angket, observasi, wawancara, dan dokumen). Untuk mengecek keabsahan data digunakan triangulasi metode dan sumber. Hasil yang diperoleh dalam penelitian ini adalah (1) perencanaan penerapan pendidikan karakter dalam pembelajaran Sejarah diawali dengan menyusun berbagai perangkat pembelajaran seperti Silabus, Format Penilaian, dan RPP. (2).Pelaksanaan pembelajaran sejarah di SMKN 1 Wonosari secara keseluruhan sudah mengintegrasikan nilai-nilai karakter, melalui tahapan pendahuluan, inti, dan penutup. (3). Penilaian pembelajaran Sejarah di SMKN 1 Wonosari berdasarkan RPP yang dibuat guru sejarah sudah meliputi penilaian afektif. Penilaian dilakukan melalui pengamatan, soal, dan diskusi klasikal. Berdasarkan hasil yang diperoleh penelitian ini, dapat disimpulkan penanaman nilai karakter dapat diintegrasikan melalui pembelajaran sejarah di SMKN 1 Wonosari.
\end{abstract}

\section{Kata Kunci: Pembelajaran Sejarah, Pendidikan Karakter}

\begin{abstract}
The purpose of this research is (1) character education planning through learning history, (2) implementation of character education through learning history, and (3) character education assessment in teaching and learning activity. This study uses a single case because the research is only done on one target (one location or one object), so that the relevant research strategy is a case study (study case). Data collection techniques using techniques nontes (questionnaires, observations, interviews, and documents). To check the validity of data used triangulation method and source. The results obtained in this study are (1) planning the application of character education in learning History begins by arranging various learning tools such as Prota, Promes, Syllabus, Assessment Format, and RPP. (2). The implementation of history learning in SMKN 1 Wonosari as a whole has integrated character values, through preliminary, core, and closing stages. (3). Historical learning assessment in SMKN 1 Wonosari based on RPP made by history teacher have included affective assessment. Assessment is done through observation, questions, and classical discussions. Based on the results obtained by this research, it can be concluded that the planting of character values can be integrated through learning history in SMKN 1 Wonosari.
\end{abstract}

Keywords: History Learning, Character Education.

\section{PENDAHULUAN}

Pendidikan mempunyai peran penting dalam proses pembangunan. Maka perbaikan sumber daya manusia juga perlu ditingkatkan

\footnotetext{
* Penulis Koresponden

E-mail address: stefan.putra84@gmail.com doi:
}

agar supaya mampu menghasilkan sumber daya yang cerdas, kreatif, mandiri juga berakhlak mulia harus terus diupayakan dalam proses pendidikan. Bersamaan dengan tujuan pendidikan Nasional, Undang-undang Sistem

Copyright@2017 Jurnal Artefak e-ISSN: 2580-0027 
Pendidikan Nasional yang dikeluarkan tahun 2003 mengenai tujuan Pendidikan Nasional pasal 3 menyatakan bahwa:
Pendidikan
Nasional
berfungsi
mengembangkan kemampuan dan
membentuk watak serta peradaban bangsa
yang bermartabat dalam rangka
mencerdaskan kehidupan bangsa bertujuan
untuk berkembangnya potensi peserta didik agar menjadi manusia yang beriman dan bertaqwa kepada TuhanYang Maha Esa: berakhlak mulia: sehat berilmu; cakap; kreatif mandiri dan menjadi warga Negara yang demokratis serta bertanggung jawab.

Dalam Undang-undang tersebut jelas bahwa peran akhlak merupakan aspek yang penting untuk mendidik anak. Pasal tersebut juga dikatakan bahwa pembentukan watak ialah usaha untuk membentuk karakter. Tujuan dari pendidikan karakter ialah penanaman nilai, didalam diri siswa juga pembaharuan tata hidup bersama, agar menghargai kebebasan individu. Tujuan jangka panjangnya ialah mendasarkan diri untuk tanggapan secara aktif dan kontekstual, individu atas impuls natural sosial yang diterima, sehingga pada gilirannya dapat mempertajam visi hidup yang ingin diraih lewat proses pembentukan diri secara terus-menerus (on going information) (Jamal, 2012: 42).

Dewasa ini banyak fenomena terkait soal kenakalan remaja yang menjadi target para pelajar, seperti perkelahian massal, school bullying, atau kekerasan dilakukan oleh guru kepada peserta didik (fatchul, 2011: 37). Tugas seorang guru harus mengubah problem diatas agar selaras, menjadikan suatu pembelajaran lebih menyenangkan dan tentunya sesuai dengan tujuan pembelajaran itu sendiri. Semua hal di atas tak bisa dilepaskan dari peran seorang guru, dalam setiap proses pembelajaran yang terjadi dalam lingkup formal maupun non formal. Dalam melaksanakan tugasnya tersebut, seorang guru prosfesional haruslah menguasai falsafah Pendidikan Nasional, mengusai pengetahuan luas khususnya pelajaran disampaikan kepada para siswa mempunyai kemampuan teknis dalam penyusunan program pangajaran dan melaksanakannya (Tilaar, 2009:89).

Berdasarkan latar belakang tersebut peneliti memfokuskan penelitian ini dalam mengkaji "Analisis Pelaksanaan Pendidikan Karakter di SMKN 1 Wonosari (Studi Kasus Pada Pembelajan Sejarah)“. Alasan memilih SMKN 1 Wonosari sebagai tempat penelitian ini karena berdasarkan informasi belum ada yang melakukan kajian pendidikan karakter di institusi ini. Rumusan masalahnya dapat dikemukakan sebagai berikut:

Bagaimana perencanaan pendidikan karakter melalui pembelajaran sejarah diSMKN 1 Wonosari?

1. Bagaimana pelaksanaan pendidikan karakter melalui pembelajaran sejarah di SMKN 1 Wonosari?

2. Bagaimana penilaian pendidikan karakter melalui pembelajaran sejarah di SMKN 1 Wonosari?

\section{Pendidikan karakter}

Pendidikan karakter menurut D. Yahya Khan yang dikutip Asmani (2013: 30) pendidikan karakter mengajarkan kebiasaan cara berpikir juga perilaku yang membantu individu untuk hidup dan bekerjasama sebagai keluarga, masyarakat, dan bangsa. Serta, membantu orang lain untuk memilih keputusan yang dapat dipertanggungjawabkan. Pendidikan karakter mengajarkan siswa atau peserta didik dapat berpikir cerdas, mengaktivasi otak tengah secara maksimal.

Menurut T. Ramli dalam Subini (2013: 23), pendidikan karakter memiliki arti dan tujuan yang sama dengan pendidikan moral dan pendidikan akhlak. Tujuannya ialah membentuk pribadi anak, agar menjadi manusia, masyarakat juga warga negara yang baik. Ada pula kriteria masyarakat atau bangsa, secara umum ialah nilai-nilai sosial tertentu banyak dipengaruhi melalui budaya masyarakat dan bangsanya.

Pendidikan karakter bisa diintegrasikan dengan pembelajaran di setiap mata pembelajaran. Setiap materi pembelajaran yang berkaitan dengan norma atau nilai-nilai disetiap mata ajar perlu dikembangkan, keeksplisitannya dikaitkan dengan kehidupannya sehari-hari. Dengan demikian pembelajaran nilai-nilai dan norma yang menjadi karakter tidak hanya berada pada tataran kognitif saja, tetapi mesti bisa menyentuh internalisasi dan pengalaman nyata dikehidupan peserta didik sehari-hari dimasyarakat (Salirawati:217).

Pendidikan ke arah terbentuknya karakter bangsa para siswa meruapakan tanggung jawab semua guru. Maka, pembinaan kepada siswa harus oleh semua guru. Pendidikan nilai dan norma dilakukan oleh semua guru yang harus menjadi sosok teladan bagi para siswanya. 


\section{Pembelajaran Sejarah}

Pengertian Sejarah menurut Sartono Kartodirdjo (1989:9-17) ialah cerita tentang pengalaman kolektif sebuah komunitas atau bangsa di masa lalu yang kemudian membentuk kepribadian nasional juga sekaligus menentukan identitas nasional bangsa tersebut. Lebih lanjut Kontowijoyo dalam Metodologi Sejarah (1994:18) mendifinisikan sejarah ialah apa yang sudah dipikirkan, dikatakan, dikerjakan, dirasakan, dan dialami manusia.

Proses pembelajaran sejarah pada dasarnya merupakan proses pendidikan yang secara umum ialah usaha mengembangkan daya manusia agar bisa membangun dirinya juga bersama sesamanya dapat membudayakan alamnya membangun masyarakat. Untuk mewujudkannya harus ditumbuhkan kesadaran sejarah yakni suatu sikap jiwa untuk memenhi secara cepat paham kesadaran sejarah yakni suatu sikap jiwa untuk memenuhi secara cepat paham tentang kepribadian nasional dan pembelajaran sejarah juga salah satu sarana menanamkan kesadaran sejarah tersebut (Kardiyat Wiharyanto, 2001:6).

Guru sejarah diharapkan mampu merangsang untuk mengenali dan mengkaji peristiwa sejarah secara utuh, dengan melakukan retruriksasi pengetahuan juga kesadaran yang dimiliki. Pembelajaran sejarah harus dapat dilakukan secara efektif. Pemebelajaran sejarah efektif ialah suatu pembelajaran ketika tidak sekedar menyampaikan sederet fakta, tetapi harus mampu mengembangkan siswa untuk mengaktualisasikan diri sesuai dengan kemampuan dan menyadari eksistensinya secara kolektif ikut menentukan masa depan bangsa (Hariyono, 1992:25).

Berdasarkan uraian di atas, maka pengertian pembelajaran sejarah adalah kegiatan belajar mengajar dalam mencari dan menemukan makna sejarah baik secara langsung atau tidak langsung sebagai keseluruhan hasil pengalaman seseorang, juga interaksinya dengan lingkungan sekitarnya yang direncanakan, dilaksanakan juga dievaluasi secara sistematis supaya peserta didik bisa mencapai tujuantujuan pembelajaran dapat tercapai.

\section{METODE PENELITIAN}

Penelitian ini menggunakan penelitian kualitatif dengan pendekatan diskriptif dan jenis penelitian studi kasus. Sumber data yang diperoleh melalui informan yaitu guru-guru sejarah yang dilakukan melalui wawancara mendalam, mengumpulkan berbagai peristiwa atau aktivitas yang dilakukan, pengambilan dokumen serta tambahan angket untuk guru sejarah di SMKN 1 Wonosari. Teknik pengumpulan data dalam penelitian ini menggunakan tehnik wawancara, observasi, dokumentasi. Tehnik Wawancara digunakan untuk menyaring data yang berkaitan dengan penanaman nilai-nilai karakter. Observasi digunakan agar memperoleh data mengenai pelaksanaan nilai-nilai karakter, dokumentasi digunakan untuk mengetahui gambaran objek yang di teliti serta angket disebarkan kepada para guru sejarah. Tehnik sampling menggunakan purposive sampling, dan validitas data yang digunakan dalam penelitian ini ialah triangulasi metode juga triangulasi sumber. Analisis data menggunakan analisis interaktif yakni reduksi data, sajian data, dan penarikan simpulan/verifikasi.

\section{PEMBAHASAN}

\section{Hasil Penelitian}

\section{Perencanaan pendidikan karakter melalui pembelajaran sejarah di SMKN 1 Wonosari}

Pendidikan karakter merupakan penanaman nilai-nilai keseharian dalam proses pembelajaran terhadap peserta didik. Sebagian besar subjek melalui wawancara menyatakan bahwa pendidikan karakter dalam pembelajaran sejarah dimulai dari guru tersebut mengajar. Seluruh subjek melakukan perencanaan implementasi pendidikan karakter dalam pembelajaran melalui pembuatan silabus dan RPP. Berdasarkan hasil angket dan wawancara, seluruh subjek menyatakan bahwa silabus dibuat setiap semester baru. Hasil angket juga wawancara menunjukkan bahwa dua orang subjek membuat RPP selalu sebelum pembelajaran. Satu subjek lainnya melalui angket dan wawancara menyatakan bahwa pembuatan RPP kadang-kadang sebelum pembelajaran.

Berdasarkan hasil angket juga wawancara, seluruh subjek melakukan perencanaan pendidikan karakter dengan selalu mencantumkan nilai karakter yang dicapai pada silabus dan RPP. Sebagian besar subjek berdasarkan hasil angket dan wawancara menyatakan dasar pemilihan nilai karakter yang 
akan dicapai yaitu ketentuan sekolah yang sejalan dengan visi misi sekolah. Hasil wawancara dengan guru yang bersangkutan menunjukkan bahwa seluruh subjek dalam kegiatan perencanaan pembelajaran memilih nilai karakter yang akan dicapai dengan penyesuaian materi, metode, strategi, dan media pembelajaran. Berdasarkan hasil tersebut bisa disimpulkan jika pemilihan nilai karakter yang akan dicapai dalam perencanaan pembelajaran dapat disesuaikan dengan ketentuan sekolah, visi misi sekolah, materi, media, strategi, dan metode pembelajaran.

\section{Pelaksanaan pendidikan karakter melalui pembelajaran sejarah di SMKN 1 Wonosari.}

Pada tahap pelaksanaan ini, semua guru telah mengintegrasikan nilai karakter dikegiatan pembelajaran. Pada tahap ini, pendidikan karakter telah diterapkan. Pembelajaran sejarah mulai dari pendahuluan, kegiatan inti, dan penutup. Sudah terlihat guru menanamkan nilai karakter bangsa seperti religius, kerja sama, disiplin, kerjakeras, percaya diri, kreatif, mandiri, peduli, tanggung jawab. Hasil wawancara yang dilakukan dengan guru bersangkutan dikatakan bahwa "Dalam setiap kegiatan belajar mengajar seorang guru selalu berusaha mengikuti langkah-langkah yang telah dibuat pada RPP yang telah diintegrasikan dengan nilai karakter bangsa agar tujuan pembelajaran dapat tercapai dengan efektif' (Hasil wawancara dengan Andreas, 32 tahun, Selasa 2 Februari 2017).

Pelaksanaan pembelajaran sejarah di SMKN 1 Wonosari berdasarkan hasil angket, secara utuh mengaktualisasi nilai karakter. Sebagian besar subjek melalui angket menyatakan materi pembelajaran selalu mengandung nilai karakter. Satu subjek lainnya menyatakan kadang-kadang materi pembelajaran mengandung nilai karakter. Berdasarkan hasil angket, subjek menyatakan nilai karakter selalu ada pada setiap kompetensi dasar.

\section{Penilaian pendidikan karakter melalui pembelajaran sejarah di SMKN 1 Wonosari.}

Berdasarkan pengamatan dalam melakukan penilaian pada aspek kognitif guru memberikan evaluasi dengan tes uraian dan pemberian tugas. Siswa mengerjakan secara individu dan guru tidak lupa untuk selalu mengingatkan tidak boleh menyontek. Penilaian nilai karakter dilakukan melalui pengamatan pada saat proses pembelajaran dan hanya sesekali saja direalisasikan. Hal ini di dukung dari hasil wawancara 1 februari 2017 untuk penilaiaan nilai karakter bapak Sutono mengungkapkan dengan mengamati dengan lembar observasi.

Berdasarkan validasi RPP, guru sejarah merencanakan penilaian sikap menggunakan lembar observasi. Aspek yang diamati adalah, religius, toleransi, kerjakeras, demokratis, semangat kebangsaan dan tanggung jawab. Adapun kriteria yang digunakan dalam lembar observasi adalah BT, MT, MB, dan MK.

\section{HASIL PENELITIAN DAN PEMBAHASAN 1. Perencanaan pendidikan karakter melalui pembelajaran sejarah di SMKN 1 Wonosari \\ Guru melakukan perencanaan} implementasi pendidikan karakter melalui pembelajaran dengan pembuatan silabus dan RPP. Berdasarkan hasil angket juga wawancara, guru menyatakan bahwa silabus dibuat setiap semester baru. Hasil angket juga wawancara itu menunjukkan, sebagian besar guru membuat RPP selalu sebelum pembelajaran. Guru lainnya melalui angket dan wawancara menyatakan bahwa pembuatan RPP kadang-kadang sebelum pembelajaran. Guru tersebut melalui kegiatan wawancara menyatakan bahwa, RPP selalu diperbaiki sebelum mengajar.

Berdasarkan hasil tersebut, dapat disimpulkan, seluruh guru sejarah di SMKN 1 Wonosari melakukan perencanaan pendidikan karakter melalui pembelajaran sejarah dengan silabus yang dibuat setiap semester baru juga RPP yang dibuat sebelum pembelajaran. Hal itu sesuai kajian teori yang didapat yaitu menurut Wibowo (2012: 86), nilai karakter yang akan dicapai dicantumkan di silabus juga RPP yang dibuat oleh pendidik.

Perencanaan implementasi pendidikan karakter, pembelajaran sejarah di SMKN 1 Wonosari dilakukan melalui pembuatan silabus dan RPP. Hal tersebut sesuai dengan kajian teori yang didapat, perencanaan pendidikan karakter dalam pembelajaran menurut Zuriah (2011: 7778) meliputi, penyeleksian dan pengorganisasian butir-butir nilai yang bisa diintegrasikan kedalam instrumen pembelajaran, serta penyeleksian pengalaman belajar layak dan bermakna dalam pembelajaran. 


\section{Pelaksanaan pendidikan karakter melalui pembelajaran sejarah di SMKN 1 Wonosari.}

Pelaksanaan pendidikan karakter melalui pembelajaran sejarah. Berdasarkan hasil penelitian di SMKN 1 Wonosari, dapat dikatakan pelaksanaan pendidikan karakter menggunakan pembelajaran sejarah sudah cukup diterapkan oleh seluruh guru sejarah. Pada tahap pelaksanaan ini, semua guru telah melakukan mengintegrasikan pada kegiatan pembelajaran yang memasukkan nilai karakter bangsa. Proses penanaman nilai karakter dalam pembelajaran sejarah meliputi: a.perencanaan, b.pelaksanaan pembelajaran (tahap-tahap pembelajaran), c. penilaian. Hal ini di sejalan dengan penelitian Anik Ghufron (2010) menyatakan bahwa, pengintegrasian nilai karakter bangsa meliputi tiga tahapan yaitu pendahuluan, inti, dan penutup, dan dalam proses pelaksanaannya diperlukan dukungan dari pihak sekolah, guru, orang tua, dan siswa.

\section{Penilaian pendidikan karakter melalui pembelajaran sejarah di SMKN 1 Wonosari.}

Berdasarkan validasi RPP, observasi juga wawancara guru sejarah telah menyiapkan instrumen tertulis dan uraian singkat. Perintah dalam instrumen jelas juga mudah dipahami oleh siswa. Pada observasi pelaksanaan, guru sudah melakukan penilaian pengetahuan yang dilakukan secara berkelompok dan soal uraian pada evalusi yang dilakukan secara individu. Siswa terlihat berusaha mencari dan menemukan jawaban dari berbagai sumber juga berusaha menyelesaikan soal tersebut (kerja keras dan tanggung jawab). Hal ini didukung oleh hasil wawancara, yang mengungkapkan bahwa penilaian pengetahuan dilakukan untuk bisa menggunakan instrumen tertulis, biasanya menggunakan soal objektif pilihan ganda juga uraian.

Berdasarkan validasi RPP, observasi dan wawancara guru sejarah merencanakan penilaian sikap menggunakan lembar observasi. Aspek yang diamati adalah, religius, toleransi, kerjakeras, demokratis, semangat kebangsaan dan tanggung jawab. Adapun kriteria yang dibuat dalam lembar observasi adalah BT, MT, MB, dan MK. Penilaian sikap siswa sudah dilaksanakan oleh guru.

Hasil penelitian ini tentunya sesuai dengan yang dikemukakan Sulistyowati (2012) bahwa penilaian pembentukan nilai karakter pada mata pelajaran lebih difokuskan pada diri peserta didik sebagai individu. Isdisusilo (2012) bahwa proses penilaian hasil pendidikan karakter terintegrasi dalam mata pelajaran berbeda dengan menilai hasil belajar sebuah mata pelajaran. Pendidikan karakter tidak diujikan secara lisan dan tulisan. Guru bisa memberikan kesimpulan/pertimbangan mengenai pencapaian suatu indikator dengan dinyatakan secara kualitatif juga memiliki makna terjadinya proses pembentukan karakter sebagai berikut: (1) BT (Belum Terlihat); (2) MT (Mulai Terlihat); (3) MB (Mulai Berkembang); dan (4) MK (Membudaya).

\section{PENUTUP}

\section{Simpulan}

Berdasarkan penelitian yang dilakukan di SMKN 1 Wonosari, dalam pelaksanaan pendidikan karakter bisa ditarik kesimpulan: 1). Dalam perencanaan pendidikan karakter melalui pembelajaran sejarah sudah mengintegrasikan nilai-nilai karakter pada setiap pembelajaran yang dilakukan. 2). Sebelum melakukan pembelajaran, guru sejarah menyiapkan terlebih dahulu pembelajarannya. Pada tahap ini, pendidikan karakter telah diterapkan dalam pembelajaran sejarah mulai dari pendahuluan, kegiatan inti dan penutup. 3) Penilaian karakter pada pembelajaran sejarah di SMKN 1 Wonosari sudah direncanakan dengan baik.

Berdasarkan hasil penelitian tentang penanaman nilai karakter pada pembelajaran sejarah di SMKN 1 Wonosari, maka disarankan untuk: 1). Pada perencanaan pembelajaran Sejarah hendaknya merencanakan secara jelas kegiatan tindak lanjut setiap pertemuan. 2). Pada Pelaksanaan pembelajaran IPS agar bisa menanamkan nilai-nilai karakter, guru hendaknya mencoba untuk melaksanakan model pembelajaran yang bervariasi seperti problem based learning, PAKEM, Dll. 3). Penilaian karakter sebaiknya direncanakan dengan baik dan dilakukan secara continue, diseimbangkan dengan penilaian aspek kognitif.

\section{DAFTAR PUSTAKA}

Asmani, Jamal Ma'mur. 2013. Buku Panduan Internalisasi Pendidikan Karakter di Sekolah. Yogyakarta: Diva Press. 
Anik Ghufron. 2010. Integrasi Nilai-nilai Karakter Bangsa Pada Kegiatan Pemblajaran. Jurnal Ilmiah Pendidikan (Nomor ISSN: 0216-1370). Hal. 13-24.

Fatchul Mu'in. 2011. Pendidikan Karakter: Kontruksi Teoritik \& Praktik. Yoyakarta:Ar-Ruzz Media.

Hariyono, 1992, "Pengajaran dan Eigenwelt Subjek Didik". Historika Nomor 6 Tahun IV. Surakarta: Program Pasca Sarjana IKIP Jakarta KPK UNS.

Kardiyat Wiharyanto, 2001, Model Pembelajaran Sejarah, Jakarta: Grafindo.

Kartodirdjo, Sartono. Fungsi Sejarah dalam Pembangunan Nasional", dalam historika no 1 tahun 1, Surakarta : Program Pasca Sarjana Pendidikan Sejarah Universitas Negeri Jakarta KPK Universitas Sebelas Maret Surakarta.

Kontowijoyo, 1994, Metodologi Sejarah. Yogyakarta; Tiara Wacana.

Isdisusilo, 2012, Panduan Lengkap Menyusun Silabus Dan RPP, Jakarta: Kota Pena.

Salirawati, Das. 2012. Percaya Diri, Keingintahuan dan Wirausaha: Tiga Karakter Penting Bagi Peserta Didik. Jurnal UNY.

Subini, Nini. 2013. Psikologi Pembelajaran. Yogyakarta: Mentari Pustaka.

Sulistyowati, Endah. 2012. Implementasi Kurikulum Pendidikan Karakter. Yogyakarta: PT Citra Aji Parama.

Tilaar, H.A.R. 2009. Membenahi Pendidikan di Indonesia. Jakarta: Rineka Cipta.

Wibowo, Agus. 2012. Pendidikan Karakter: Strategi Membangun Karakter Bangsa Berperadaban. Yogyakarta: Pustaka Pelajar.

Zuriah, Nurul. 2011. Pendidikan Moral dan Budi Pekerti Dalam Prespektif Perubahan. Jakarta: Bumi Aksara.

Undang-undang Nomor 20 Tahun 2003 Tentang Sistem Pendidikan Nasional pasal 3. Jakarta: Eka Jaya. 